\title{
A Influência da Reputação Corporativa no Custo de Capital
}

\section{The Influence of Corporate Reputation on Cost of Capital}

\author{
Divino Martins de Jesus Mestre em Ciências Contábeis. Fucape Business School - Brasil. \\ https://orcid.org/0000-0001-8031-5958 \\ Silvania Neris Nossa \\ https://orcid.org/0000-0001-8087-109X \\ Valcemiro Nossa \\ https://orcid.org/0000-0001-8091-2744 \\ Nadia Cardoso Moreira \\ https://orcid.org/0000-0002-9085-6595 \\ paixaocaipirapai@terra.com.br. \\ Doutora em Ciências Contábeis e Administração. Fucape Business School - Brasil. \\ silvanianossa@fucape.br \\ Doutor em Controladoria e Contabilidade. Fucape Business School - Brasil. \\ valcemiro@fucape.br \\ Doutora em Ciências Contábeis e Administração. Fucape Business School - Brasil. \\ nadiacmoreira@fucape.br
}

\section{RESUMO}

Esta pesquisa verifica se existe relação entre o custo de capital e a reputação das empresas mensurada pelo ranking do Monitor Empresarial de Reputação Corporativa (MERCO). Esta pesquisa contribui para a literatura trazendo uma nova proxy para a mensuração da reputação das empresas (ranking do MERCO). Além disso, no ambiente brasileiro não foi encontrado nenhum outro estudo que relaciona de forma direta a reputação corporativa com o custo de capital. A contribuição deste estudo se dá num contexto em que devido às fontes escassas e onerosas de financiamento, conhecer o custo de capital e exercer uma gestão eficaz dos recursos disponíveis, são fatores preponderantes para a sobrevivência das empresas em um mercado competitivo. A pesquisa foi realizada utilizando o método de regressão linear múltipla estimada por Efeitos Fixos com erros robustos. A amostra é composta pelas empresas listadas da B3 nos períodos de de 2013, 2014, 2016 e 2017, sendo o número de observações final igual a 897 . O ano de 2015 ficou fora da amostra porque neste ano não ocorreu a publicação do ranking MERCO. Os resultados indicam que empresas listadas na B3 ranqueadas pelo MERCO apresentam menor custo de capital do que as demais, independentemente da posição em que a empresa se encontra no ranking da MERCO.

Palavras-chave: custo de capital; ranking; reputação corporativa; B3; MERCO.

\begin{abstract}
This research verifies if there is a relation between the cost of capital and the reputation of the companies measured by the Corporate Monitor of Corporate Reputation (MERCO) ranking. It contributes to the literature, bringing a new proxy for measuring the reputation of companies (MERCO ranking). In addition, no other study was found in the Brazilian environment that directly relates corporate reputation to the cost of capital. The contribution of this study takes place in a context in which, due to the scarce and costly sources of financing, knowing the cost of capital and exercising an effective management of the available resources, are preponderant factors for the survival of companies in a competitive market.The research used the multiple linear regression method estimated by Fixed Effects with robust errors. The sample is made up of B3 listed companies in the periods of 2013,2014, 2016 and 2017, with the final number of observations equal to 897. The year 2015 was out of the sample because this year the MERCO ranking was not published. The results indicate that companies listed on B3 ranked by MERCO have a lower cost of capital than the others, regardless of the position in which the company is in the MERCO ranking.
\end{abstract}

Keywords: cost of capital; ranking; corporate reputation; B3; MERCO. 


\section{INTRODUÇÃO}

A evidenciação de informações contábeis pelas entidades tem sido fator preponderante para a continuidade das operações das empresas. Tanto as informações voluntárias como as compulsórias podem resultar em credibilidade junto ao meio no qual estão inseridas, convertendo-se em vantagem competitiva tanto para as empresas envolvidas quanto para os investidores e fornecedores de capital.

De acordo com o Global Reporting Initiative (2015), as organizações têm procurado tornar suas operações mais sustentáveis e transparentes, onde muitas, geralmente com frequência de um ano, prestam contas por meio de relatórios nos quais são evidenciadas medidas de desempenho, estabelecimento de objetivos e monitoramento das mudanças operacionais, objetivando fornecer informações aos diversos grupos de interesse sobre gastos com folha de pagamento, encargos sociais, participações nos resultados, gastos com controle ambiental, investimentos sociais internos e externos em cultura, educação, lazer e saúde entre outros.

Segundo Scharf (2004), empresas que buscam o sucesso por meio da sustentabilidade devem estar sempre atentas à necessidade de prestar contas à sociedade por meio de relatórios transparentes de sustentabilidade (anuais) abordando o desempenho socioambiental. Para esta autora, este relatório deve conter vários indicadores referentes ao desempenho social, ambiental e econômico, visando ampliar o diálogo com os stakeholders.

A Teoria da Divulgação tem sido objeto de discussão por diversos estudiosos, buscando esclarecer a influência da publicação de informações de cunho financeiro, visando entender, dentre outros aspectos, quais são as razões econômicas que justificam que determinadas informações sejam divulgadas(Lima, 2007).

Para Castro (2008), mesmo se tratando de um tema relevante, a Responsabilidade Corporativa (RC) passou a merecer maior atenção somente na década de 1990. Destarte, para este autor, o assunto é visto pelo mercado como relativamente novo, se apresentando, portanto, um campo fértil para pesquisas.

De acordo com Villafañe (2009) a reputação corporativa está ganhando foco no meio empresarial fazendo com que, de maneira crescente, a RC passe a ser considerada como um ativo importante e imprescindível para as organizações. Rêgo (2010), defende que as empresas sempre foram compostas de dois lados, um que é mensurável e de fácil atribuição de valor, e outro, que é incorpóreo e se caracteriza pela dificuldade de mensuração em razão da subjetividade. Dentre os itens tangíveis são lembrados, por exemplo, os pontos de venda e seus produtos. Como intangíveis, o atendimento, a simpatia, a credibilidade, dentre outros elementos. Para esta autora, atualmente, o que se observa é um movimento diferente, no qual muitas pesquisas têm sido realizadas para encontrar mecanismos que possam contribuir para valorar de forma justa os intangíveis.

A pesquisa em por objetivo identificar se o custo de capital é impactado pela reputação das empresas listadas no ranking MERCO, comparando-as com aquelas que fazem parte da B3, apenas. Adicionalmente, $\mathrm{o}$ presente estudo visa averiguar também se a posição ocupada pelas empresas no referido ranking (que classifica as empresas de 1 a 100), pode ou não influenciar no custo de capital.

$\mathrm{Na}$ literatura nacional, apesar de não haver estudos que relacionam o efeito das empresas com reputação corporativa diretamente com custo médio de capital, o trabalho de Callegari, Gonçalves, Serrano e Rodrigues (2016), que analisaram as empresas listadas pelo ISE (Índice de Sustentabilidade Empresarial) da B3, detentoras de elevados atributos de RC e encontraram evidências de uma considerável redução no custo de capital próprio de tais empresas.

Em 2000, surgiu o MERCO, como opção inovadora para a formação de um ranking contemplando as cem melhores empresas do ano e, a partir de então, se constituiu em uma das mais respeitadas entidades na apuração anual da reputação das empresas, valendo-se de um método próprio e inédito objetivando ranqueálas de forma ordinal.

Pelo exposto, a expectativa é que as empresas constantes no ranking MERCO apresentem custo de capital menor que as demais empresas, principalmente a longo prazo, dado que são classificadas no referido ranking em razão de sua boa reputação e por atuarem também em prol das sociedades nas quais estão estabelecidas. 
Assim, a motivação do estudo, além do fato do tema RC ser pouco explorado na área contábil e de finanças, também se justifica pela inovação da metodologia utilizada pelo MERCO, uma vez que, até então, diversas pesquisas que examinaram o custo de capital utilizaram como proxy outras referências ou rankings originados de revistas especializadas, jornais ou periódicos, com objetivos mesclando interesses comerciais.

Neste estudo as empresas classificadas nas posições próximas de 1 são consideradas as empresas com maior nível de reputação enquanto empresas classificadas nas posições próximas de 100 são consideradas com menor nível de reputação, conforme o MERCO. Os resultados encontrados vieram ao encontro da hipótese formulada, pois foram encontradas evidências de que as empresas ranqueadas pelo MERCO apresentam menor custo de capital. As empresas que estão entre as melhores ranqueadas no MERCO e as empresas que estão entre as piores ranqueadas pelo MERCO têm custo de capital reduzido em comparação às empresas que não estão no MERCO.

Desta forma, neste estudo tem-se o grupo de tratamento formado pelas empresas classificadas no ranking $\mathrm{MERCO}$ e as demais empresas da B3, que não constam no ranking MERCO, que fazem parte do grupo de controle, buscando resposta para a questão de pesquisa: O fato das empresas estarem listadas no ranking MERCO exerce influência sobre o seu custo de capital, se comparadas àquelas que não fazem parte do ranking MERCO?

\section{FUNDAMENTAÇÃO TEÓRICA}

\subsection{O Merco}

O surgimento do MERCO (Monitor Empresarial de Reputação Corporativa) criado no ano 2000, parece bastante oportuno, porque abrange empresas de todos os portes, ramos de atividade e com presença nos mais diversos países do mundo.

O Instituto Análisis e Investigación, entidade responsável pela elaboração do MERCO, com sede na Espanha, é um monitor de referência no mundo. Trata-se de um instrumento de avaliação reputacional, sendo o único monitor no mundo a utilizar uma metodologia multistakeholder, presente em 11 países entre Europa e América Latina, que trabalha a partir de cinco avaliações e onze diferentes fontes de informação. Além do ranking das empresas, o MERCO elabora outros cinco rankings: MERCO Líderes, MERCO Responsabilidade e Governança Corporativa, MERCO Talento, MERCO Consumo e MERCO MRS (Monitor de Reputación Sanitária). No Brasil, o MERCO consolidou-se como o primeiro ranking euro-americano de reputação, também é parceiro do IBOPE (Instituto Brasileiro de Opinião Pública e Estatística) para a realização do ranking, que teve sua primeira edição em 2013 e posteriormente em 2014, 2016 e 2017.

De acordo com o Instituto Analisis e Investigación, outro diferencial é que o MERCO é totalmente independente, tanto que é o primeiro monitor empresarial auditado no mundo, sendo que, seu processo de elaboração e seus resultados são objeto de auditoria independente pela KPMG, um dos quatro maiores escritórios de auditoria do mundo. $O$ instituto enfatiza a questão da transparência, pois todos os critérios de ponderação são públicos e disponíveis para consulta e sua metodologia de avaliação é considerada a mais completa e uma das mais rigorosas do mundo em razão da quantidade de fontes de informação consultadas, conforme Tabela 1.

\begin{tabular}{c|l|c}
\hline Número & Fontes de informação/Grupo respondente & Percentual \\
\hline 01 & Comitês de direção & $33 \%$ \\
\hline 02 & Analistas financeiros & $6 \%$ \\
\hline 03 & ONGs & $4 \%$ \\
\hline 04 & Sindicatos & $4 \%$ \\
\hline 05 & Membros de associações de consumidores & $4 \%$ \\
\hline 06 & Jornalistas de informes econômicos & $6 \%$ \\
\hline 07 & Consultores de empresas & $4 \%$ \\
\hline 08 & Gestores de mídia & $4 \%$ \\
\hline 09 & Consumidores & $10 \%$ \\
\hline 10 & Pessoas/talentos & $10 \%$ \\
\hline 11 & Avaliadores de méritos & $15 \%$ \\
\hline
\end{tabular}

Tabela 1 - Segmentos respondentes do questionário MERCO

Fonte: Elaborado pelos autores com dados do MERCO (2016). 
Conforme apresentado na Tabela 1, o MERCO tem por objetivo valorar as onze facetas que contribuem para a reputação de uma empresa. Para isso o Instituto Análisis e Investigación utiliza um processo estruturado em diversas etapas, com o objetivo de tabular os dados procedentes das diferentes fontes de informação, cujo resultado final é um índice que serve como base para a confecção do ranking, que é publicado anualmente.

De acordo com Manuel Sevillano, diretor global do MERCO, a metodologia utilizada inclui cinco ondas de avaliação. A seleção parte de uma entrevista com membros da alta direção de empresas com faturamento superior a U\$ 40 milhões/ano, que apontam 10 companhias com melhor reputação no ano que se finaliza. Para cada empresa escolhida, sinalizam três fortalezas e uma fraqueza entre dezoito variáveis que consideram resultados econômicos e financeiros, qualidade da oferta comercial, talento, ética e reponsabilidade corporativa, dimensão internacional e inovação. Esses são os atributos utilizados para traçar o perfil de reputação das empresas. (MERCO, 2019)

Antes do surgimento do MERCO, os estudos sobre RC consideravam como proxies de reputação corporativa diversos outros rankings divulgados em revistas especializadas e outros informativos, dentre eles: as empresas mais admiradas do Brasil, as mais valiosas marcas brasileiras, as 500 empresas campeãs de vendas no Brasil, as 100 empresas com maior valor de mercado do Brasil, As maiores e melhores segundo a Revista Exame, empresas listadas no ISE da B3, empresas listadas na Revista Carta Capital, as empresas com maior sustentabilidade de acordo com a mídia e as 100 maiores de capital aberto, entre outros.

Mas havia uma lacuna, conforme se verifica na pesquisa de Cruz e Lima (2010), na qual fica evidente a dificuldade para encontrar a proxy adequada para representar a reputação das empresas brasileiras, chegando a citar o índice ISE com certo tom crítico porque, para estes autores, o ISE é cópia fiel do índice Dow Jones. Desta forma, as pesquisas realizadas anteriormente ao surgimento do MERCO, para estes autores, careciam de um índice mais preciso e confiável.

Assim, para Pinto, Freire e Santos (2015), o surgimento do Monitor de Reputação MERCO, que começou a ranquear as empresas com operações no Brasil a partir de 2013, veio como opção para as pesquisas relacionadas ao tema reputação. Daí em diante começaram a surgir novas pesquisas ligadas ao tema reputação.

\subsection{A Teoria da Divulgação}

Para Coco (2000), a ideia da sinalização tem sido utilizada nos mais diversos cenários do ambiente econômico, nos mais diversos segmentos, dentre outros, em processos industriais, mercado de capitais, propagação de modelos de política econômica, onde os diversos componentes de uma transação emitem sinais que possibilitam ao mercado uma espécie de depuração e segregação entre as partes envolvidas em um contrato.

Spence (1973), precursor da teoria da sinalização, inicialmente a aplicou nos ambientes de trabalho. O autor, inicialmente valeu-se do raciocínio de Jonh Hasany, onde propôs uma forma de associar a teoria dos jogos com a assimetria de informações. Para tanto, utilizou como referência o nível de educação dos trabalhadores, visto como um sinal de qualidade pelos empregadores, fato que poderia resultar em maior produtividade por parte dos indivíduos.

Quanto a divulgação de informações de caráter socioambiental, de acordo com Gray e Bebbington (2001), o tema tem ganhado grande importância e tem se firmado como uma das maiores manifestações por parte das empresas quanto à interação com o meio ambiente, e tal notabilidade se dá, sobretudo, quando a divulgação ocorre de forma voluntária. Em sua pesquisa, Epstein (2003), destaca o aumento do número de empresas que elaboram relatórios socioambientais, mas entende que a qualidade das informações prestadas não tem aumentado no mesmo ritmo. Assim, com base na literatura, espera-se que a inclusão do nome das empresas no ranking MERCO, possa ser vista pelo mercado como um sinal positivo. 
Recentemente a divulgação de condutas supostamente ilícitas envolvendo grandes corporações como a Enron, Worldcom, Nike, Exxon Valdez, entre outras, tem despertado consumidores e investidores de todo o mundo.

Apresenta-se a seguir um quadro contemplando alguns dos principais estudos sobre a teoria da divulgação com seus respectivos resultados.

\begin{tabular}{|c|c|c|c|}
\hline Autores & Objetivo & $\begin{array}{c}\text { Metodologia/local do } \\
\text { estudo }\end{array}$ & Resultado \\
\hline Coco (2000) & $\begin{array}{l}\text { Verificar junto ao mercado se } \\
\text { as informações colaterais } \\
\text { minimizam a assimetria de } \\
\text { informações. }\end{array}$ & $\begin{array}{lrr}\text { Estudo das } & \text { garantias } \\
\text { oferecidas ao } & \text { mercado } \\
\text { visando mitigar a escassez de } \\
\text { oferta de } & \text { crédito. } \\
\text { investimentos. } & \end{array}$ & $\begin{array}{l}\text { A sinalização minimiza a } \\
\text { assimetria e indica maior } \\
\text { comprometimento do } \\
\text { empresário, resultando em } \\
\text { maior confiança do mercado. }\end{array}$ \\
\hline $\begin{array}{l}\text { Spence } \\
\text { (1973) }\end{array}$ & $\begin{array}{l}\text { Associar a teoria dos jogos à } \\
\text { assimetria de informações } \\
\text { buscando verificar se o nível } \\
\text { de educação do trabalhador é } \\
\text { sinal de qualidade. }\end{array}$ & $\begin{array}{l}\text { Estudou sobre o poder da } \\
\text { educação, experiência, raça, } \\
\text { sexo, cor e outras } \\
\text { particularidades observáveis } \\
\text { como diferenciais para os } \\
\text { indivíduos, na visão do } \\
\text { mercado de trabalho. }\end{array}$ & $\begin{array}{l}\text { Encontrou correlação positiva } \\
\text { entre a educação e a melhoria } \\
\text { dos rendimentos dos } \\
\text { empregados com melhor nível } \\
\text { de conhecimento, por causa do } \\
\text { aumento da confiança dos } \\
\text { empregadores. }\end{array}$ \\
\hline $\begin{array}{l}\text { Gray e } \\
\text { Bebbington } \\
(2001)\end{array}$ & $\begin{array}{l}\text { Analisar a relação entre a } \\
\text { publicação de relatórios } \\
\text { ambientais de forma } \\
\text { voluntária e a confiança dos } \\
\text { stakeholders. }\end{array}$ & $\begin{array}{l}\text { Estudou questões voltadas ao } \\
\text { meio ambiente e aos aspectos } \\
\text { sociais buscando verificar se } \\
\text { há interesse da contabilidade } \\
\text { ambiental, em razão dos altos } \\
\text { custos envolvidos. }\end{array}$ & $\begin{array}{l}\text { Apesar dos elevados custos de } \\
\text { divulgação, a evidenciação } \\
\text { voluntária aumenta a confiança } \\
\text { dos stakeholders. }\end{array}$ \\
\hline
\end{tabular}

Quadro 1 - Estudos sobre a teoria da divulgação com seus resultados

Fonte: Elaborado pelos autores (2021).

\subsection{A Relevância da Reputação Corporativa para as Empresas}

Estudos sobre o tema Reputação Corporativa (RC) tem sido realizados há algumas décadas, mas foi a partir da década de 90 que passou a despertar maior interesse por parte de pesquisadores das mais variadas áreas do conhecimento, passando pela sociologia, pela estratégia, pela teoria das organizações, pela economia como também pela contabilidade (Fombrun \& Van Riel, 2007).

Para Whetten e Mackey (2002), RC é o retorno para a empresa, das partes interessadas, relacionandose com a credibilidade que esta demonstra. A RC é relativamente estável, porque leva tempo para ser construída, torna-se difícil que apenas uma medida seja capaz de capturar as diversas percepções acerca do tema.

Visando equalizar esta questão, Fombrun (1996) propõe que a RC pode ser aferida por meio de uma parcela representativa de diversas partes interessadas e a condição é que esta aferição seja realizada fazendo uso de critérios relevantes.

Diante da pluralidade de áreas que têm se dedicado a estudar o tema $\mathrm{RC}$, cada uma com objetivos distintos, surge a possibilidade da divisão destes estudos sob dois pontos de vista abrangentes, sendo o primeiro sob o olhar da filosofia, que se propõe a definir o que é reputação e quais os constructos que devem ser levados em conta para sua formação, e a segunda corrente, que se propõe a medir a reputação por meio do impacto financeiro causado às organizações (Lloyd, 2007).

Na visão dos que defendem a RC como geradora de vantagens, uma elevada RC passa para o mercado uma boa imagem da empresa, convertendo-se em dez vantagens distintas, sendo que, dentre estas, ao menos quatro são de cunho financeiro, a saber: (i) minimização dos riscos para ao detentores do capital; (ii) facilitação junto ao mercado de capitais na obtenção de recursos destinados a alavancagem de novos projetos; (iii) captação de recursos a taxas menores; (iv) baixo nível de endividamento (Fombrun \& Van Riel, 2007; Caminiti, 1992; Brown, 1997; Fombrun, 1996; Roberts \& Dowling, 2002; Rossoni \& Guarido Filho, 2015).

Em pesquisa realizada em 2008 pela Harris Interactive, apurou-se que $71 \%$ dos consumidores estadunidenses entendem que a reputação das empresas do país se posiciona entre as piores. De acordo com 
a pesquisa, gigantes como a Google, $3 \mathrm{M}$ e Coca-Cola, figuraram entre as dez mais bem pontuadas, enquanto outras, também gigantes, como GM, Ford e Shell, figuraram entre as piores. Vale ressaltar que a realização da pesquisa (edição do Harris Interactive Reputation Quotient) ocorreu pouco tempo antes do início da crise mundial da economia, cujo início se deu nos EUA.

Um ponto interessante a se destacar nesta pesquisa é que diversos trabalhos têm sido realizados, sempre associando RC e desempenho empresarial e tendo como referência as revistas e institutos mais conceituados e com grande credibilidade nos países de primeiro mundo, sobretudo nos EUA, em vários países da Europa e no Japão, todos com a presença maciça das grandes corporações do planeta em seus territórios, onde os habitantes detêm elevado grau de entendimento em relação a informação contábil.

Para Hall Jr. e Lee (2014), apesar de existir na literatura, amparado por diversos trabalhos que comprovam empiricamente a relação entre elevada $\mathrm{RC}$ e desempenho financeiro superior, estes autores alertam o mercado para o fato de que a associação de elevada RC com desempenho financeiro superior tem sido verificada em pesquisas que têm como base empresas norte-americanas e empresas estabelecidas na Europa e que, nos países fora desse universo, as pesquisas são ainda incipientes e necessitam de ampliação.

Sabate e Puente (2003), buscaram associar empiricamente RC positiva e melhor desempenho financeiro e encontraram que: nos EUA, a associação da RC positiva é mais ligada ao desempenho financeiro. Já, nos países Europeus, as variáveis de cunho financeiro dão lugar às variáveis sociais. Em razão de ser algo relativamente novo, é de se esperar que a RC também seja objeto de estudo em locais onde o processo de instalação de grandes empresas ou de suas subsidiárias esteja sendo implementado recentemente. Assim, Mitra, Green e Dutra (2013), verificaram que há uma forte tendência em promover estudos sobre RC nos países emergentes, em razão do aumento da influência que estes têm alcançado em relação à economia global. Na mesma linha, Newburry e Soleimani (2010), encontraram que, estudos sobre RC em países de terceiro mundo são escassos e destacam ainda que tais estudos, apesar de poucos, têm sido mais recorrentes na China, ficando os países da américa latina para segundo plano.

Góis (2015) pesquisou sobre a relação entre a $\mathrm{RC}$ e a geração de riqueza nas empresas componentes do índice da $\mathrm{B} 3$ e chegou à conclusão que a $\mathrm{RC}$ impacta positivamente a criação de riqueza.

Em seus estudos, Pinto, Freire e Santos (2015), buscaram comparar o retorno das ações das empresas ranqueadas pelo MERCO com o retorno das ações das empresas listadas no ISE da B3, visando apurar se há diferença significativa entre os valores encontrados para estes dois grupos que possuem, de acordo com o mercado, elevada $\mathrm{RC}$, e chegaram à conclusão de que as ações de empresas ranqueadas pelo $\mathrm{MERCO}$, possuem maior retorno.

Ferreira, Medeiros Silva (2015), analisaram a influência das reportagens veiculadas na mídia em relação à posição das empresas brasileiras listadas no ranking MERCO e concluíram que estas reportagens afetam a posição no ranking, sobretudo quando apontam envolvimento em situações comprometedoras, maus resultados financeiros e notícias ambientais, tanto positivas quanto negativas.

Tentando estabelecer relação entre fatores tangíveis e intangíveis, Pinto et al. (2015), se propôs a responder se a RC pode ser afetada pelos indicadores de desempenho. Para tanto tomou como base os estudos de Fombrun e Shanley (1990), que apontam que uma boa RC tem associação positiva com a performance financeira superior. Chegou a um resultado contrário ao que era esperado, porque encontrou evidências de que uma boa performance financeira não aumenta o índice de RC, mas uma RC elevada é que leva a uma boa performance financeira.

\begin{tabular}{|c|c|c|c|}
\hline Autores & Objetivo & Metodologia/local do estudo & Resultado \\
\hline $\begin{array}{c}\text { Whetten e } \\
\text { Mackey } \\
\text { (2002) }\end{array}$ & $\begin{array}{l}\text { Estudar as diferentes } \\
\text { necessidades } \\
\text { organizacionais das } \\
\text { empresas. }\end{array}$ & $\begin{array}{l}\text { Utilizaram analogia afirmando } \\
\text { que a identidade seria uma } \\
\text { autobiografia da empresa } \\
\text { promovida por seus gestores. }\end{array}$ & $\begin{array}{l}\text { Encontraram que as organizações } \\
\text { podem apresentar diversas } \\
\text { identidades ao mesmo tempo, } \\
\text { rejeitando-se a ideia de durabilidade } \\
\text { e uniformidade. }\end{array}$ \\
\hline $\begin{array}{c}\text { Fombrun } \\
\text { (1996) }\end{array}$ & $\begin{array}{l}\text { Aferir a } \quad \text { RC } \quad \text { das } \\
\text { empresas por meio de } \\
\text { representantes das } \\
\text { partes interessadas. }\end{array}$ & $\begin{array}{l}\text { Estudo da comunicação } \\
\text { corporativa como forma de } \\
\text { fortalecer a RC em termos de } \\
\text { aferição, conhecimento e estima }\end{array}$ & $\begin{array}{l}\text { RC é o resultado das ações passadas } \\
\text { da empresa, bem como de sua visão } \\
\text { de futuro, se comparada a outras, } \\
\text { podendo converter-se em vantagem }\end{array}$ \\
\hline
\end{tabular}




\begin{tabular}{|c|l|l|l|}
\hline & & $\begin{array}{l}\text { por parte dos grupos de } \\
\text { relacionamento. }\end{array}$ & intangível. \\
\hline $\begin{array}{c}\text { Roberts e } \\
\text { Dowling } \\
(2002)\end{array}$ & $\begin{array}{l}\text { Estudaro impacto da RC } \\
\text { no desempenho } \\
\text { organizacional das dado de amostra formada } \\
\text { empresas. }\end{array}$ & $\begin{array}{l}\text { Estudo } \\
\text { pelas empresas componentes do } \\
\text { ranking das empresas mais } \\
\text { admiradas, da Revista Fortune. }\end{array}$ & $\begin{array}{l}\text { Encontraram correlação entre RC e } \\
\text { desempenho persistente. }\end{array}$ \\
\hline
\end{tabular}

Quadro 2 - Estudos sobre reputação corporativa com seus resultados

Fonte: Elaborado pelos autores (2021)

\subsection{Custo de Capital e Reputação Corporativa}

Para Schroeder, Clark e Cathey (2016), o custo de capital das firmas é definido pelo resultado da equação entre o valor de recursos próprios e o valor de recursos de terceiros envolvidos na estrutura. Modigliani e Miller (1958), em seu trabalho pioneiro, concluíram não haver relação atribuída quanto a combinação entre capital próprio e de terceiros, exceto quanto ao benefício gerado pela dedutibilidade dos impostos.

De acordo com Copeland, Koller e Murrin (2000, p. 220), o custo do capital é dado pelo percentual mínimo de resultado que a empresa necessita auferir por meio de suas operações, o que corresponde a uma remuneração mínima que precisa ser alcançada para que sejam mantidos de maneira satisfatória o valor das ações e a continuidade do negócio, bem como garantir seu crescimento de forma sustentável. Para este autor, - Weighted Average Cost of Capital (WACC), ou custo médio ponderado de capital, corresponde ao mecanismo utilizado para trazer a valor presente os fluxos de caixa estimados para o tempo futuro, mediante aplicação de determinada taxa de remuneração, geralmente aquela pretendida pelo detentor do capital.

Já Hail (2002), valendo-se de procedimento semelhante, analisou 73 firmas suíças não atuantes no setor financeiro e encontrou forte associação negativa, com alto grau de significância, entre o custo de capital e o nível de disclosure. Chen, Wei e Chen (2003), se propuseram a analisar, sob uma outra visão, a relação do custo de capital com o nível de disclosure. Eles acrescentaram outros indicadores relacionados à governança corporativa e encontraram que o disclosure, bem como os indicadores de governança corporativa não relacionados ao disclosure contribuem para a diminuição do custo de capital.

Em seus estudos, Roberts e Dowling (2002) encontraram evidências de que uma elevada RC exerce influência positiva no desempenho financeiro. Assim, identificaram que empresas com altos níveis de $\mathrm{RC}$ conseguem auferir e sustentar bons níveis de lucro ao longo do tempo.

Pelo fato do MERCO representar uma nova proposta metodológica para a medição da RC, espera-se que a presença das empresas no referido ranking possa contribuir para a redução do custo médio ponderado de capital. Neste sentido, em diversos estudos similares, tem-se atribuído à redução do custo de capital a fatores como a divulgação de relatórios de sustentabilidade, relatórios sobre responsabilidade social e sobre boas práticas de Governança Corporativa (Hail, 2002; Jandik \& Mc Cumber, 2013; Novaes \& Almeida, 2020; Silva, Xavier, Gambirage, \& Camilo, 2018).

Quanto à RC, analisando empresas ranqueadas pela Revista Dinheiro, sob o título "As melhores da Dinheiro", Callegari, Gonçalves, Serrano e Rodrigues (2016) encontraram que empresas com elevado índice de evidenciação social tendem a apresentar menor custo de capital próprio, corroborando com os achados de Fombrum (1996), que relaciona RC a um menor custo de capital.

Levando-se em conta que o ranking MERCO classifica as empresas que ocupam as cem primeiras posições anualmente (de 1 a 100) segundo a métrica da RC, espera-se que as empresas ranqueadas apresentem menor custo médio ponderado de capital, se comparadas àquelas constantes da B3, apenas, originando assim a hipótese de pesquisa:

\section{H1: Empresas ranqueadas no MERCO apresentam menor custo de capital.}

Complementarmente, considerando-se uma divisão das empresas em dois grupos sendo: empresas classificadas nas melhores posições (de 1 a 50) e empresas classificadas nas piores posições (de 51 a 100). Espera-se que as empresas melhor classificadas, posições (de 1 a 50), apresentem menor custo médio ponderado de capital, se comparadas àquelas pior classificadas, posições (de 51 a 100), originando assim a 
segunda hipótese de pesquisa.

H2: A posição ocupada pelas empresas no ranking MERCO influência de maneira diferente o custo de capital.

\section{METODOLOGIA DE PESQUISA}

As abordagens realizadas por esta pesquisa são caracterizadas de forma quantitativa e descritiva, utilizando o método de regressão linear múltipla, caracterizada em painel de efeito fixo e com erros robustos. A amostra é composta pelas empresas ranqueadas pelo MERCO nos períodos de 2013, 2014, 2016 e 2017, sendo o número de observações igual a 897.0 ano de 2015 ficou fora da amostra porque neste ano não ocorreu a publicação do ranking MERCO.

Portanto, foram utilizadas todas as empresas listadas no banco de dados Economatica, nos anos de 2013, 2014, 2016 e 2017, perfazendo 2.217 informações. Deste total, após os tratamentos de limpeza pelo Software Stata, restaram 897 observações. As empresas dos segmentos bancário e securitário foram mantidas visando minimizar o empobrecimento da amostra e também porque muitas delas estão listadas no ranking MERCO.

O ranking MERCO é formado por empresas listadas e não listadas pela Brasil Bolsa Balcão - B3, além de conter empresas de outros países. Assim, foi realizada uma seleção manual e apurou-se que: em 2013, 31 das 100 empresas ranqueadas no MERCO faziam parte da B3 e disponibilizavam as informações no banco de dados Economatica, em 2014 a proporção foi de 34 para 100, em 2016 foi de 37 para 100 e em 2017 foi de 32 para 100.

O modelo 1 descrito na equação (1) a seguir, utiliza como proxy de reputação a variável binária MERCO e visa testar se as empresas ranqueadas pelo MERCO apresentam menor custo de capital. As características das variáveis definidas no modelo são descritas na Tabela 2.

Equação (1):

$$
\begin{gathered}
W_{A C C_{t}=\beta 0+} \beta 1 D_{t}+\beta 2 \text { Tangib }_{t}+\beta 3 \text { Liq }_{-} \text {Acao }_{t}+\beta 4 \text { Valor_Mercado }_{t}+\beta 5 M T B_{t}+\beta 6 T A M_{t} \\
+\beta 7 R_{0} A_{t}+\epsilon_{t}
\end{gathered}
$$

Em que:

WACC $=$ Custo médio ponderado de capital da empresa i no período $t$;

D_merco = Variável dummy da empresa no período t, representando a reputação, sendo 1 para empresas ranqueadas e zero para empresas não ranqueadas;

Tangibilidade $=$ Tangibilidade da empresa i no período $t$;

Liquidez_ação = Liquidez da ação i no período t;

Valor_Mercado = Valor de mercado da empresa i, dado pelo logaritmo natural do AT, no período t;

MTB $=$ Market to book da empresa i no período t;

Tamanho = Tamanho da empresa i no período t;

$\mathrm{ROA}=$ Retorno sobre o ativo i no período $\mathrm{t}$.

Como base para definição do cálculo do custo de capital (WACC), utiliza-se os achados de Damodaran (1997) alinhado com a expressão de cálculo definida por Ross, Westerfield e Jaffe (1997, p. 271), Copeland, Koller e Murrin (2000) pois, conforme os autores, é fortemente difundida e válida, tanto no ambiente acadêmico como no meio empresarial, sendo apresentada pela seguinte expressão de cálculo:

Em que:

$$
W A C C=K e * E / D+E * K{ }^{*} D / D+E *(1-I R)
$$

WACC $=$ Custo médio ponderado de capital;

$\mathrm{Ke}=$ Custo de capital próprio dos acionistas;

$\mathrm{Kd}=$ Custo da dívida;

$\mathrm{E}=$ Patrimônio líquido (equity);

$\mathrm{D}=$ Dívida total;

$\mathrm{IR}=\mathrm{Imposto}$ de renda incidente sobre os lucros da empresa.

Logo:

$E / D+E=W e=$ proporção do capital correspondente ao patrimônio líquido;

$\mathrm{D} / \mathrm{D}+\mathrm{E}=\mathrm{Wd}=$ proporção do capital correspondente à dívida. 
Para a definição do custo de capital de terceiros (Ki) foram utilizadas premissas de Assaf Neto (2003, p. 356) e Gitman (2010, p.438), sendo a taxa obtida realizando-se a divisão das Despesas Financeiras (DF) pelo montante da Dívida Total Bruta (DTB), multiplicado por 1, subtraindo-se a alíquota do Imposto de Renda e da Contribuição Social (somadas), por meio da seguinte expressão de cálculo:

$$
\mathrm{Ki}-(\mathrm{DF} / \mathrm{DTB}) * 1(1-\mathrm{T})
$$

Em que:

$\mathrm{Ki}=$ Custo do capital de terceiros;

DF $=$ Despesas Financeiras;

DTB = Dívida Total Bruta (montante de todos os empréstimos e financiamentos a curto e longo prazo);

$\mathrm{T}$ = Alíquota do Imposto de Renda e da Contribuição Social (somadas).

Finalmente, para estimar o custo do capital próprio foi utilizado o CAPM (Capital Asset Price Mode), sendo na visão de Damodaran (1997, p. 271) e Assaf Neto (2003, p. 271) largamente utilizado no campo das finanças, que permite a determinação, de forma consciente, quanto ao risco de um ativo, evidenciado na seguinte expressão de cálculo:

$$
R j=R f+B E T A(R m-R f)
$$

Em que:

$\mathrm{Rj}=$ retorno esperado do ativo;

$\mathrm{Rf}=$ retorno do ativo livre de risco;

$\mathrm{Rm}=$ retorno de mercado (IBOVESPA).

$\mathrm{BETA}=$ medida de risco da empresa em relação ao mercado.

O modelo descrito na equação (2) a seguir, busca testar se existe relação entre a posição de uma empresa no ranking do MERCO e o seu custo de capital, utilizando-se a posição da empresa como proxy de reputação. Para o modelo (2) será medido o efeito do custo de capital das empresas ranqueadas nas melhores colocações, ou seja, aquelas posicionadas entre 1 e 50 em relação as empresas ranqueadas nas piores colocações, ou seja, aquelas posicionadas de 51 a 100. As características das variáveis definidas no modelo são descritas na Tabela 2.

Equação (2):

$$
\begin{gathered}
\text { WACC }_{t}=\beta 0+\beta 1 D 1 a 50_{t}+\beta 2 D 51 a 100_{t}+\beta 3 \text { Tangib }_{t}+\beta 4 \text { Liq_Acao }_{t}+\beta 5 \text { Valor_Mercado }_{t}+\beta 6 M T B_{t} \\
+\beta 7 T_{A} M_{t}+\beta 8 R O A_{t}+\epsilon_{t}
\end{gathered}
$$

Em que:

WACC $=$ Custo médio ponderado de capital da empresa i no período t;

D1-50 = Posição baixa da empresa i, período t, conforme critérios do MERCO;

D51-100 = Posição alta da empresa i, período t, conforme critérios do MERCO;

Tangibilidade $=$ Tangibilidade da empresa i no período t;

Liquidez_ação = Liquidez da ação i no período t;

Valor_Mercado $=$ Valor de mercado da empresa $\mathrm{i}$, dado pelo logaritmo natural do AT, no período t;

MTB $=$ Market to book da empresa i no período t;

\begin{tabular}{|c|c|c|c|c|}
\hline $\begin{array}{l}\text { Nome da } \\
\text { variável }\end{array}$ & Tipo & Sigla & Expressão de cálculo & Fonte \\
\hline $\begin{array}{l}\text { Custo de } \\
\text { Capital }\end{array}$ & Dependente & WACC & $\begin{array}{c}\text { WACC }=K e^{*} E / D+E * K d * \\
D / D+E *(1-I R)\end{array}$ & $\begin{array}{l}\text { Schroeder, Clark e Cathey, } \\
(2016) .\end{array}$ \\
\hline MERCO & Independente & D_merco & $\begin{array}{l}\text { Dummy } 1 \text { empresas ranqueadas } \\
\text { e } 0 \text { empresas não ranqueadas }\end{array}$ & $\begin{array}{l}\text { Instituto Análisis e e } \\
\text { Investigación, Villafañe, (2009). }\end{array}$ \\
\hline Posição baixa & Independente & D1-50 & $\begin{array}{c}\text { Dummy } 1 \text { empresas ranqueadas } \\
\text { nas posições de } 1 \text { a } 50 \text { e } 0 \text { para } \\
\text { as demais empresas }\end{array}$ & $\begin{array}{l}\text { Instituto Análisis e } \\
\text { Investigación, Villafañe, (2009). }\end{array}$ \\
\hline
\end{tabular}

Tamanho = Tamanho da empresa i no período t;

$\mathrm{ROA}=$ Retorno sobre $\mathrm{o}$ ativo $\mathrm{i}$ no período $\mathrm{t}$.

A Tabela 2, apresenta a caracterização das variáveis do modelo descrito nas equações (1) e (2): 


\begin{tabular}{|c|c|c|c|c|}
\hline Posição Alta & Independente & D51-100 & $\begin{array}{c}\text { Dummy } 1 \text { empresas ranqueadas } \\
\text { nas posições de } 51 \text { a } 100 \text { e } 0 \\
\text { para as demais empresas }\end{array}$ & $\begin{array}{l}\text { Instituto Análisis e } \\
\text { Investigación, Villafañe, (2009). }\end{array}$ \\
\hline Tangibilidade & Controle & TANGIB & Ativo Imobilizado/ Ativo Total & Arellano e Bond, (1991) \\
\hline Liquidez ação & Controle & Liq_ação & Quão rápido se vende a ação & B3 \\
\hline $\begin{array}{l}\text { Valor de } \\
\text { mercado }\end{array}$ & Controle & VM & $\frac{\text { No ações * preço da ação }}{\text { Ativo }}$ & $\begin{array}{l}\text { Peres e Famá (2003); } \\
\text { Fernández (2001) }\end{array}$ \\
\hline $\begin{array}{l}\text { Market to } \\
\text { book }\end{array}$ & Controle & MTB & $\frac{\mathrm{VM}}{\mathrm{PL}}$ & Santana et al. (2003) \\
\hline Tamanho & Controle & TAM & Logaritmo natural do AT & $\begin{array}{l}\text { Claessens, Djankov, Fan e } \\
\text { Lang, (1999); }\end{array}$ \\
\hline $\begin{array}{l}\text { Retorno sobre } \\
\text { o ativo }\end{array}$ & Controle & ROA & Lucro operacional/Ativo & Westerfield e Jordan, (2013) \\
\hline
\end{tabular}

Nota: As variáveis D1-50 e D51-100 fazem parte da estimação na equação 2 e a variável D_Merco faz parte da equação 1.

Tabela 2 - Características das variáveis da pesquisa

Fonte: Elaborado pelos autores (2021).

\section{ANÁLISE DE RESULTADOS}

A estatística descritiva das variáveis analisadas com base nos modelos 1 e 2, para testar as hipóteses deste estudo traz indicações de um custo médio ponderado de capital de 5,41 em relação às 897 empresas analisadas. Os resultados nos quartis sugerem que as empresas melhor posicionadas no ranking MERCO possuem menor custo de capital, ou seja, 1,08 para o quartil (P25) e 4,35 para o quartil (P50), enquanto que as empresas em posições superiores apresentam em média um custo médio ponderado de capital de 8,7 para o quartil (P75) e 28,39 para o quartil (P100) (Tabela 3).

Por meio da análise de correlação Pearson (univariada) entre as variáveis, com base nos modelos $1 \mathrm{e}$ 2, com as correlações ao nível de 1\% de significância é possível observar que as variáveis independentes não apresentam alta correlação com o custo médio ponderado de capital. E que não se verificou correlação alta entre as variáveis explicativas. Adicionalmente fez-se a análise de multicolinearidade entre as variáveis explicativas com o teste VIF, mas não se verificou nenhum problema com multicolinearidade.

$\mathrm{Na}$ Tabela 3 apresenta-se o resultado da regressão com base no modelo 1 e modelo 2, tendo o WACC como variável dependente em relação a empresa fazer ou não, parte do ranking MERCO no modelo 1 e a posição 1 a 50 no ranking da empresa na MERCO dummyum e zero nos demais casos modelo2.

\begin{tabular}{|c|c|c|c|c|}
\hline \multicolumn{3}{|c|}{ Modelo1 } & \multicolumn{2}{|c|}{ Modelo 2} \\
\hline & Coeficiente & p-valor & Coeficiente & p-valor \\
\hline MERCO & -1.95578 & $0.000^{* * * *}$ & -1.95578 & $0.000^{* * *}$ \\
\hline ROA & -0.0381123 & $0.000 * * *$ & -0.0381123 & $0.000 * * *$ \\
\hline TANGIB & -0.8755208 & 0.26600 & -0.8755208 & 0.26600 \\
\hline LIQUID_AÇÃO & 0.4006406 & 0.36100 & 0.4006406 & 0.36100 \\
\hline MTB & -0.1018772 & $0.008^{* * *}$ & -0.1018772 & $0.008^{* * *}$ \\
\hline VM & 0.8206265 & $0.000^{* * *}$ & 0.8206265 & $0.000 * * *$ \\
\hline CONSTANTE & -0.7081687 & 0.09400 & -0.7081687 & 0.09400 \\
\hline R2 ajustado & 0.4847 & & 0.4847 & \\
\hline Prob $>$ F & 0.0000 & & 0.0000 & \\
\hline Média VIF & 1,12 & & 1,12 & \\
\hline Observações & 893 & & & \\
\hline Controle ano & Sim & & & \\
\hline
\end{tabular}

Nota: Os asteriscos representam: coeficiente estatisticamente significante *a 10\%, * a $5 \%$ e *** a $1 \%$.

Tabela 3 - Regressão linear com o custo médio ponderado de capital (wacc) como variável dependente em relação à listagem no merco

Fonte: Elaborado pelos autores (2021). 
Esta tabela apresenta a regressão com o efeito da interação entre as variáveis de controle e a variável explicada, sendo composta por 893 observações. MERCO Monitor de reputação, considerando a variável dummy 1 para empresas listadas e dummy 0 para empresas não listadas. ROA retorno sobre o ativo da empresa i ano t. TANGIBILIDADE Ativo imobilizado/ativo total da empresa i ano t. LIQUIDEZ DA AÇÃO O quão rápido se vende a ação da empresa i ano t. MTB Market to book, é calculado pela fração do valor de mercado e o patrimônio líquido da empresa i no ano t. VM Valor de mercado capturado diretamente na base de dados Economática $n^{\circ}$ de ações * preço de venda/ativo.

O modelo 1 objetiva testar se a presença das empresas no ranking MERCO resulta em menor custo de capital. O resultado demonstra que a variável (MERCO) apresentou um coeficiente negativo e estatisticamente significativo ao nível de $1 \%$ de significância, evidenciando que as empresas que fazem parte do ranking MERCO apresentam menor custo de capital, validando a primeira hipótese do estudo (Tabela 3).

Embora não haja estudos que relacionam reputação corporativa com o custo de capital, os resultados encontrados estão em linha com trabalhos similares, a exemplo de Robinson, Kleffner, Bertels e Arbor (2008) que evidenciaram a relação positiva entre a sustentabilidade corporativa, a reputação corporativa e o valor da firma; Silva e Quelhas (2006), que demonstraram que empresas com elevado índice de sustentabilidade empresarial influenciam na redução do custo de capital próprio;

Também Murcia et al. (2011), encontraram relação inversa entre transparência e risco, onde o risco menor sinaliza para menor custo de capital.

\begin{tabular}{cccc}
\hline WACC & Coeficiente & Erro Padrão & p-valor \\
\hline D1-50 & -2.340763 & 0.885326 & $0.008^{* * *}$ \\
D51-100 & -1.772890 & 0.548995 & $0.001^{* * *}$ \\
ROA & -0.382498 & 0.008742 & $0.000^{* * *}$ \\
TANGIBILID. & -0.884078 & 0.786983 & 0.26200 \\
LIQUID_AÇÃO & 0.4261915 & 0.440024 & 0.33300 \\
VM & 0.8237839 & 0.2198452 & $0.000^{* * *}$ \\
MTB & -0.1018266 & 0.0381885 & $0.008^{* * *}$ \\
CONSTANTE & -0.7123948 & 0.4225291 & 0.09200 \\
F-Sig & 0,00000 & & \\
RQ & 0,4848 & & \\
Média VIF & 1,11 & & \\
Controle ano & Sim & &
\end{tabular}

Nota: Os asteriscos representam: coeficiente estatisticamente significante *a 10\%, ** a 5\% e *** a 1\%. Tabela 4 - Regressão linear múltipla com o custo médio ponderado de capital (wacc) como variável dependente em relação à posição ocupada pelas empresas no monitor de reputação merco Fonte: Elaborado pelos autores (2021).

Esta tabela apresenta a regressão com o efeito da interação entre as variáveis de controle, as variáveis de interesse e a variável explicada, sendo composta por 893 observações. D1-50 posição das empresas i, no ano t, no ranking do MERCO. D51-100 posição das empresas i, no ano t, no ranking do MERCO. ROA retorno sobre o ativo da empresa i ano t. TANGIBILIDADE Ativo imobilizado/ativo total da empresa i ano t. LIQUIDEZ DA AÇÃO O quão rápido se vende a ação da empresa i ano t. VM Valor de mercado capturado diretamente na base de dados Economatica $n^{\circ}$ de ações * preço de venda/ativo. Market to book, é calculado pela fração do valor de mercado e o patrimônio líquido da empresa i no ano $t$.

O modelo 2 traz o custo médio ponderado de capital como variável dependente em relação às posições ocupadas pelas empresas no ranking MERCO. Esse modelo busca testar se as empresas que se encontram nas melhores posições no ranking MERCO possuem uma maior influência na redução do custo médio ponderado de capital. Para tanto as empresas ranqueadas foram segregadas em duas posições, ou seja: 
variável D1-50, contendo as empresas posicionadas de 1 a 50 e variável D51-100, contendo as empresas posicionadas de 51 a 100 (Tabela 4).

Em relação às empresas posicionadas de 1 a 50 os resultados evidenciam um coeficiente negativo de $-2,34$ e significativo a um nível de $1 \%$ de significância, enquanto que as empresas posicionadas de 51 a 100 apresentaram um coeficiente negativo de $-1,77$ a um nível de $1 \%$ de significância.

Diante do resultado apresentado na Tabela 4, partiu-se para o teste estatístico para verificar se a dimensão do beta de D1-50 é estatisticamente diferente da dimensão do beta de D51-100, e o resultado foi de que não há diferença estatisticamente significante entre os betas de D1-50 e D51-100, ao se observar Prob $>F$ $=0,5282$. Diante do exposto pode-se concluir que estar no ranking do Merco tem influência no custo de capital, mas a posição não é um fator importante.

Assim, o resultado sugere que empresas listadas no ranking da MERCO apresentam uma redução no custo médio ponderado de capital em relação as empresas que não estão ranqueadas no MERCO. Desta forma foi testada a segunda hipótese de pesquisa. Os resultados encontrados também se assemelham aos achados de Dhaliwal, Li, Tsang e Yang (2011), que encontraram evidências de que o social disclosure é primordial para a melhoria da RC, contribuindo assim para um menor custo de capital próprio.

\section{CONCLUSÃO E CONTRIBUIÇÃO}

O propósito do estudo foi avaliar se a presença das empresas brasileiras de capital aberto no ranking MERCO contribui para que estas apresentem menor custo de capital e, de maneira complementar, verificar se a posição ocupada pelas empresas no ranking MERCO influencia de maneira diferente o custo de capital. Para tanto, foram observadas as empresas relacionadas na B3, nos anos de 2013, 2014, 2016 e 2017. Em 2015, o ranking não foi publicado.

O resultado foi que as empresas ranqueadas pelo MERCO apresentam menor custo de capital, independentemente da posição ocupada, sinalizando poder informativo para o mercado. Este resultado vai ao encontro de estudos similares que buscaram explicar se há relação entre a sustentabilidade corporativa, a reputação corporativa, e o valor da firma, a exemplo de Robinson, Kleffner, Bertels e Arbor (2008), corroborando também com o estudo de Silva e Quelhas (2006) que encontraram que empresas envolvidas em questões de sustentabilidade empresarial tendem a apresentar redução do custo de capital próprio.

Verificou-se que as empresas ranqueadas pelo MERCO nas posições de 1 a 50, tendem a apresentar menor custo de capital nos dois grupos. Ou seja a posição não é fator importante para influenciar o custo de capital. Ou seja, o simples fato de estar no ranking MERCO reduz o custo de capital.

Verificou-se algumas limitações para a pesquisa, sendo a principal delas o fato do ranking MERCO ser relativamente novo. Assim, só possível utilizar os dados de 2013, 2014, 2016 e 2017, o que deixa margem para a realização de estudos futuros, visando ampliar as discussões sobre o tema.

O ranking MERCO contempla apenas 100 empresas a cada ano e, deste total, apenas cerca de 1/3 fazem parte da B3. Sugere-se como objeto para novas pesquisas, ampliar o período e avaliar também se o custo de capital das empresas S.A. que não fazem parte da B3 é impactado pela presença destas no ranking MERCO.

O estudo contribui com a literatura sobre custo de capital devido ao fato de que diversas pesquisas tem sido realizadas, sempre utilizando como proxy outras referências ou rankings publicados por revistas especializadas, jornais e outros periódicos, todos com algum objetivo comercial. Assim, o presente trabalho traz como diferencial o fato de utilizar como proxy um ranking relativamente novo, que utiliza em sua confecção uma metodologia diferenciada, isenta de objetivos comerciais para a medição da RC. Quanto à contribuição para o mercado, traz informações que podem levar os gestores, sobretudo da área de finanças, a uma melhor compreensão quanto a importância da relação entre a RC e o custo de capital para as entidades. Para os usuários externos a contribuição vem no sentido de alertar os diversos agentes do mercado, tais como: instituições financeiras, analistas, investidores, entidades reguladoras, governo e sociedade em geral, quanto a necessidade de reavaliarem o seu grau de confiança em relação às empresas analisadas. 


\section{REFERÊNCIAS}

Assaf Neto, A. (2003). Finanças corporativas e valor. São Paulo: Atlas.

Brown, B. (1997). Part IV: How Do Reputations Affect Corporate Performance?: Stock Market Valuation of Reputation for Corporate Social Performance. Corporate Reputation Review, 1(1), 76-80.

Caminiti, S. (1992). The payoff from a good reputation. Fortune, 125(3), 74-77.

Castro, D. J. D. (2008). Como se constrói uma 'reputação corporativa'?(Dissertação de mestrado, Fundação Getúlio Vargas). Recuperado de: https://bdtd.ibict.br/vufind/Record/FGV_bcbb41a30567bdbc7ce7475eee723797

Chen, K. C., Wei, K. C., \& Chen, Z. (August, 2003). Disclosure, corporate governance, and the cost of equity capital: evidence from Asia's emerging markets. Corporate Governance, and the Cost of Equity Capital: Evidence from Asia's Emerging Markets.

Claessens, S., Fan, J. P., Djankov, S., \& Lang, L. H. (1999). On expropriation of minority shareholders: evidence from East Asia. Policy Research Working Paper Series. Washington: The World Bank.

Coco, G. (2000). On the Use of Collateral. Journal of Economic Surveys, 14(2), 191-214.

Copeland, T., Koller, T., \& Murrin, J. (2000). Avaliação de Empresas "Valuation". São Paulo: Makron Books.

Cruz, C. V. O. A., \& Lima, G. A. S. F. (2010). Corporate reputation and disclosure level in open capital Brazilian companies. Revista Universo Contabil, 6(1), 85-101.

Damodaran, A. (1997). Avaliação de investimentos - Ferramentas e técnicas para a determinação do valor de qualquer ativo. Rio de Janeiro: Qualitymark.

Dhaliwal, D. S., Li, O. Z., Tsang, A., \& Yang, Y. G. (2011). Voluntary nonfinancial disclosure and the cost of equity capital: The initiation of corporate social responsibility reporting. The accounting review, 86(1), 59-100.

Epstein, M. J. (2003). The identification, measurement, and reporting of corporate social impacts: past, present and future. Advances in Environmental Accounting and Management, Amsterdam, 2(1), 1-29.

Fernández, P. (2001). Company valuation methods: The most common errors in valuation. Madrid: IESE Business School.

Fombrun, C., \& Van Riel, C. (1997). The Reputational Landscape. Corporate Reputation Review, London, 1(1-2), 1997.

Fombrun, C. J., \& Van Riel, C. B. M. (2007). The reputational landscape. Corporate Reputation Review, 1(2), 513.

Fombrun, C. (1996). Reputation: Realizing Value from the Corporate Image. Boston: Harvard Business School Press.

Gitman, L. J. (2010). Princípios de administração financeira (12. ed.). Porto Alegre: Bookman.

Global Reporting Initiative (2015). Elaboração de relatórios de sustentabilidade, 2015. Recuperado em https://www.globalreporting.otg/resourcelibrary/GRIG4-Part.I-Reporting-Principles-and-standardDisclosures.pdf.

Góis, A. D. (2015). Reputação corporativa: constructos e implicações para a criação de valor. (Dissertação de Mestrado, Universidade Federal do Ceará). Recuperado de: http://www.repositorio.ufc.br/handle/riufc/15094

Gray, R., \& Bebbington, J. (2001). Accounting for the environmental (2. ed.). London: Sage.

Hail, L. (2002). The impact of voluntary corporate disclosures on the ex-ante cost of capital. The European Accounting Review, 11(4), 741-773.

Hall Jr., E. H., \& Lee, J. (2014). Assessing the impact of firm reputation on performance: an international point of view. International Business Research, 7(12), 1-13.

Jandik, T., \& McCumber, W. R. (2013). Governance, takeover probability, and the cost of private debt. Journal of Finance Management, Markets and Institutions, 1, 111-132. 
Lloyd, S. (2007). Corporate reputation: Ontology and measurement (Doctoral dissertation, Auckland University of Technology). Auckland, Nova Zelandia.

MERCO. (2019). Apresentação da quinta edição do rankingranking anual das 100 empresas mais responsáveis e com melhor governança corporativa no Brasil. Recuperado em 20 de janeiro, 2020, de http://www.merco.info/br/ ranking-merco-responsabilidad-gobierno-corporativo.

Mitra, R., Green, R. J., \& Dutta, M. J. (2013). Corporate reputation in emerging markets: A culture-centered review and critique. Handbook of communication and corporate reputation, 484-496.

Modigliani, F., \& Miller, M. H. (1958). The cost of capital, corporation finance and the theory of investment. The American, 1(3), 261-297.

Newburry, W.; Soleimani, M. A. (2010). Multi-level reputation signals in service industries in Latin America. Innovar Journal, 21(39), 191-203.

Novaes, P. V., \& Almeida, J. E. (2020). The Role of Firms' Life Cycle Stages on Voluntary Disclosure and Cost of Equity Capital in Brazilian Public Companies. Brazilian Business Review, 17(6), 601-620.

Pinto, L. J. S., Freire, F. S., \& Santos, M. A. C. (2015). Retorno das ações com status de reputação corporativa no Brasil: Um estudo comparativo entre empresas ranqueadas no MERCO e empresas listadas no ISE BM\&F BOVESPA. RAGC, 4(9).57-75.

Rêgo, A. R. (2010). O crescente valor da Reputação Corporativa no ambiente mercadológico. Anais do $4^{\circ}$ Congresso Brasileiro Científico de Comunicação Organizacional e de Relações Públicas, Abracorp, Porto Alegre, RS, Brasil, 4.

Roberts, P. W., \& Dowling, G. R. (2002). Corporate reputation and sustained superior financial performance. Strategic Management Journal, 23(12), 1077-1093.

Robinson, M., Kleffner, A., Bertels, S., \& Street, C. (2008, September). The value of a reputation for corporate social responsibility: Empirical evidence. In A. Krous (Chair), Governance II. Anais do 2008 Northern Finance Association Conference, Kananaskis Village, Canada.

Ross, S. A., Westerfield, R., \& Jordan, B. D. (1997). Princípios de administração financeira (2. ed.). São Paulo: Atlas.

Rossoni, L., \& Guarido Filho, E. R. (2015). O que faz um nome? Status, conselho de administração e características organizacionais como antecedentes da reputação corporativa. Revista de Administração, 50(3), 292-309.

Sabate, J. M. F., \& Puente, E. Q. (2003). Empirical analysis of the relationship between corporate reputation and financial performance: A survey of the literature. Corporate Reputation Review, 6(2), 161-177.

Scharf, R. (2004). Manual de negócios sustentáveis. São Paulo: Amigos da Terra.

Schroeder, R. G., Clark, M. W., \& Cathey, J. M. (2016). Financial Accounting Theory and Analysis: Text and Cases: Text and Cases. New Jersey: Wiley Global Education.

Silva, L. S. A. D., \& Quelhas, O. L. G. (2006). Sustentabilidade empresarial e o impacto no custo de capital próprio das empresas de capital aberto. Gestão \& Produção, 13(3), 385-395.

Silva, J. C., Xavier, W. G., Gambirage, C., \& Camilo, S. P. O. (2018). The Influence of Political Connections on the Cost of Capital and the Performance of Companies Listed on B3. Brazilian Business Review, 15(4), 317 330.

Spence, A. M. (1973). Job Market Signaling. The Quarterly Journal of Economics, 83(3), 355-374.

Villafañe, J. (2009). La Reputacion Corporativa como expression de una nueva racionalidade empresarial. Recuperado de: www.lacocletera.com/myfiles/...estrategica/Justo\%20Villafane.pdf

Whetten, D. A., \& Mackey, A. (2002). A social actor conception of organizational identity and its implications for the study of organizational reputation. Business \& society, 41(4), 393-414. 